\title{
Annual Report October 1993-September 1994
}

We have had another excellent year. The total number of papers submitted to Thorax has increased yet again (table 1). Our overall acceptance rates for original articles and case reports remain steady at $46.7 \%$ and $23 \%$ respectively.

Despite the further increase in throughput the reviewing time for original manuscripts has fallen from a median of 79 days last year to 73 days this year (table 2). Time for the first verdict for case reports is a little longer than 1992-3 but the differences are relatively small.

We have attempted to encourage submissions from outside the UK to reflect the true international status of Thorax. Table 3 shows the gratifying increase in submissions both from North America and other European countries. Japan and Australia are also sending us more work. This increased level of awareness for Thorax is reflected both in the larger number of papers accepted from outside the UK and also in the sales of the journal at the reduced subscription rate available to individual members of foreign thoracic societies around the world. The half price subscription for individuals who belong to thoracic societies other than the BTS has proven most attractive. The offer remains open and the Editorial Board are committed to making the journal as widely read as possible and hope the gradually rising number of subscriptions for Thorax will continue as it has done over the last three years.

We are pleased with the response to the Short Paper

Table 1 Articles submitted by category

\begin{tabular}{lccc}
\hline & 1992 & 1993 & 1994 \\
\hline Original papers & 370 & 415 & 410 \\
Case reports & 204 & 219 & 242 \\
Editorials & 27 & 44 & 34 \\
Review series & 16 & 24 & 6 \\
Scientific up-dates & 4 & - & - \\
Short papers & - & - & 14 \\
Supplement articles & - & - & 12 \\
Case report commentaries & - & - & 3 \\
Total & 621 & 702 & 721 \\
\hline
\end{tabular}

Table 2 Decision times for submitted papers, 1993-4

\begin{tabular}{lrr}
\hline & Original papers & Case reports \\
\hline Number & 433 & 195 \\
Median time to first decision (days) & 73 & 62 \\
Papers resubmitted (n) & 172 & 33 \\
Median time to final decisions (days) & 24 & 8 \\
\hline
\end{tabular}

Table 3 Geographical distribution of submissions

\begin{tabular}{lccc}
\hline & $\begin{array}{l}1992 \\
(n=621)\end{array}$ & $\begin{array}{l}1993 \\
(n=702)\end{array}$ & $\begin{array}{l}1994 \\
(n=721)\end{array}$ \\
\hline UK & 277 & 257 & 253 \\
Western Europe & 167 & 179 & 220 \\
Spain & 35 & 40 & 50 \\
Netherlands & 30 & 27 & 35 \\
Italy & 9 & 21 & 28 \\
France & 17 & 18 & 19 \\
Turkey & 15 & 15 & 15 \\
Israel & 15 & 10 & 15 \\
Eire & 10 & 12 & 13 \\
Switzerland & 8 & 7 & 12 \\
Germany & 10 & 13 & 11 \\
Belgium & 7 & 9 & 9 \\
Greece & 3 & 3 & 9 \\
Austria & 7 & 4 & 3 \\
Portugal & 1 & 0 & 1 \\
USA and Canada & 48 & 81 & 100 \\
Japan & 37 & 44 & 47 \\
Australasia & 18 & 32 & 32 \\
Scandinavia & 25 & 38 & 27 \\
Asia & 32 & 35 & 22 \\
Eastern Europe & 6 & 9 & 6 \\
South America & 1 & 9 & 5 \\
Africa & 4 & 6 & 5 \\
Middle East & 6 & 12 & 4 \\
\hline
\end{tabular}

Table 4 Impact factor and cited half-life of manuscripts, 1993

\begin{tabular}{llll}
\hline & Impact factor & $\begin{array}{l}\text { Cited half-life } \\
\text { (years) }\end{array}$ & Rank \\
\hline Am Rev Respir Dis & $4 \cdot 72$ & $6 \cdot 8$ & 1 \\
Am $\mathcal{F}$ Respir Cell Mol Biol & 3.55 & $2 \cdot 6$ & 2 \\
Thorax & 2.41 & $7 \cdot 4$ & 3 \\
$\mathcal{F}$ Thorac Cardiovasc Surg & 2.33 & $8 \cdot 2$ & 4 \\
Eur Respir $\mathcal{F}$ & $2 \cdot 01$ & $3 \cdot 2$ & 5 \\
Chest & 1.59 & $5 \cdot 7$ & 7 \\
Respir Med & $1 \cdot 0$ & $3 \cdot 1$ & 11 \\
\hline
\end{tabular}

section. An increasing number of manuscripts are being presented as 1400 word papers. These vary from an important negative study to a preliminary communication or a paper making a small but important point which can be stated succinctly.

Case reports remain a significant and popular part of the journal. In order to make these more valuable and less anecdotal, the case report Associate Editor is organising commentaries on collections of three to four case reports to set them in better perspective as an educational exercise. The first of these will appear early in 1995 .

There is no doubt that Thorax is flourishing. It is under constant pressure to expand as more papers, reviews and editorials are produced. The current policy of three editorials an issue, including directed editorials, will continue into 1995 as will the review series, some of which have been turned into books - a further popular development of the last few years.

We are always open to suggestions; we certainly would encourage correspondence on published papers as we only receive about 40 letters per year. It is hoped to send a questionnaire to the readership during 1995 to assess satisfaction, new ideas, etc.

Our wish expressed in last year's annual report for more paediatric respiratory papers is looking promising. However, we must continue to strive for submissions in those areas of respiratory medicine that we seem in constant danger of losing to other specialities - lung cancer, intensive care, and HIV-related subjects.

\section{Citation index and cited half-life of manuscripts}

In 1992 the citation index for Thorax jumped from 1.8 to $2 \cdot 4$. As you will see from table 4 this excellent level has been maintained. The impact factor for the American Thoracic Society journals has fallen whilst the $E R \Im$ has improved from 1.5 to $2 \cdot 0$. The relationship between the ERf andThorax remains excellent with the stimulus of healthy competition, and both are now strongly challenging the ATS journals. There is room enough for two major European respiratory journals and it is good to see them both doing well.

The cited half-life for manuscripts accepted by Thorax remains excellent at $7 \cdot 4$ years, and is bettered by only one other respiratory journal. Thorax has moved up to third place in the overall ranking for respiratory journals worldwide. Authors are now increasingly sending their best work to the journal and if this trend continues the impact factor will surely rise again.

All those who have reviewed manuscripts for Thorax have made an important contribution to the improving standard of the journal. Reviewing is often an apparently thankless task but, if well done, helps to maintain the value of the peer review system. All our reviewers are listed on page 1280 and their contribution is gratefully acknowledged. 